\title{
Relating Improved Picture Quality to Adoption of Digital Camera: A Survey of Nigerian Magazines
}

\author{
Emmanuel Ifeduba and Feyisope Sadiq \\ Department of Mass Communication, Redeemer's University, Mowe, Ogun State, Nigeria,
}

\begin{abstract}
This study primarily examined the relationship between the adoption of digital cameras and the improved picture quality in Nigerian magazines. It also investigated the relationship between improved printing skill, improved photographic skill, improved paper quality and improved picture quality in the selected magazines. A total of 320 journalists were surveyed and a response rate of $91.4 \%$ was attained. Data were statistically analyzed using the Statistical Package for the Social Sciences (SPSS) and presented in tables and charts. The results indicate that there is a relationship between improved picture quality in the magazines and the adoption of digital camera as well as improved skills and paper quality. It is, therefore, concluded that though digital cameras play significant role in improving the quality of published photographs, they constitute only a factor among others such as photographic skills, printing skills and paper quality all which contribute more significantly to published picture quality. Considering that the study is limited to offline magazines, it is recommended that a similar study covering online magazines, newspapers and other publications should be conducted in order to arrive at more generalizable conclusions.
\end{abstract}

Key Words: Photography, Innovation, Adoption, Nigeria, Photographic Quality

\section{Background to the Study}

For many years photography has been an integral part of journalism but the quality of photographs used in local Nigerian magazines has hardly measured up to international standards until recently. Considering that it was only in the 1990s that the first commercially available digital camera was developed, scholars have generally speculated that improved photographic qualities in many countries might be attributed to the coming of digital cameras ( Curtin, 2007; Zelten, 2002; Ifeduba, 2010). This thinking is heightened by the fact that almost all facets of human activities have been directly or indirectly influenced by advances in information and communication technology, ICT, especially in the media sectors (Azi, 2013).

In Nigeria, the effect of the global revolution in ICT is overwhelming. Information and communication technologies have provided a wide array of possibilities for increasing the quality, quantity, speed and distribution of information. Some of these functions come with positive values complementing the status quo (Ekeanyanwu, 2009). Consequently there has been a widespread expansion and adoption of information technologies leading to the provision of more efficient, better and faster means of communication. One of those numerous innovations is the digital camera.

Currently, photojournalists who have the skill are utilizing hi-tech gadgets and digital cameras can be put on automatic mode for easier operation; and many routine functions hitherto performed in the darkroom can now be performed with the click of a button on digital gadgets. The digital age has also brought about flexibility, availability, accessibility and affordability, thereby expanding the frontiers of photography, as well as all the tools in its practice. Journalism, according to Azi (2013) is one of the professions benefitting immensely from this digital transformation.

At the same time, improvements have been recorded in the areas of photographic paper, printers, chemicals and lights. These variables make it difficult to attribute improved photographic quality in Nigerian magazines to any specific factor without first undergoing an empirical investigation. For instance, it is difficult to say if the improvement in the quality of photographs in Nigerian magazines should be attributed to improved skills, improved knowledge acquired by photojournalists or the adoption of digital cameras? Are better printing machines, higher quality photographic papers or better chemicals used in printing responsible for the observed improvement in photo quality? Or is the observed improvement traceable to the use of digital cameras as against analogue cameras that have been in use for hundreds of years? These questions set the background for this study.

\section{The Problem}

Magazine publishing in Nigeria has faced many technical challenges ranging from poor print quality to poor photographic quality probably because some magazine houses in Nigeria still make use of outmoded equipment. Whereas some photojournalists working for these magazines do not know which of the competing 
technologies to adopt for optimal performance, many of those that have upgraded their equipment and software have failed to provide their staff with adequate training necessary for the realization of the full potentials of newly adopted equipment.

Many of them may have introduced digital camera technology because of the immediacy and convenience it provides and because it is popular and trendy. At a time when photographic quality is improving, it is not clear whether digital cameras are responsible for better quality images neither is there evidence that digital camera images are preferable to analogue images. Against the backdrop of other improving factors such as paper quality, camera handling skills, printing skills and technique, it becomes absolutely necessary that a clear understanding of the relationship between improved photo quality and adoption of digital cameras should begin with an empirical investigation.

Furthermore, many studies have been done in various areas of journalism and photojournalism but the impact of digital cameras on photo-journalism has not received adequate attention in literature. The few studies that have been conducted have no empirical and theoretical focus on Nigeria. This is a major gap in the literature that this paper intends to address.

\section{Research Questions}

The following questions are posed to guide the study: Is there any relationship between the adoption of digital cameras and the improved photographic quality in Nigerian magazines? Is there any relationship between the adoption of digital cameras and the reduction of photographic noise in Nigerian magazines? Is there any relationship between improved printing skill and improved photographic quality in Nigerian magazines? What is the relationship between improved photographic quality and quality of paper used?

\section{Literature and Theoretical Framework}

Digitization of the photographic process did not start with digital cameras. Instead, it started with the digitization of analogue images using scanners. The technique was developed by NASA scientists in the 1960s so that they could electronically send images taken in space down to earth. The first electronic camera was created by an engineer, Steve Sasson, at Eastman Kodak in 1974. It made use of a charge-coupled device image sensor and the first still video camera was introduced by Sony in 1981. It was the first electronic camera, though not digital, and eliminated the darkroom stages in film photography and the scanning stage in early photography. The Charge-Coupled Device Sensor (CCD Sensor) is the heart of digital imaging. It was conceived and developed in the 1970s at Bell Laboratories mainly for medicine, astronomy and scientific professionals who used them where high quality image data was needed (Zelten, 2002).

The first set of commercially available digital cameras appeared in the 1990s, though not without challenges. For instance, though the pictures could be quickly uploaded onto a computer, it didn't provide photojournalists with instant viewing device that is one of the major advantages of digital camera over analogue cameras (Zelten, 2002). When complementary Metal Oxide Semiconductor (CMOS) censors for digital cameras were introduced, they came with had higher quality but did poorly in the market, though they offered lower prices and small size considered more important than quality. In the past 10 years many developing countries, including Nigeria, have also adapted to changing technology leading to easier access to computers, Internet and mobile technology. This development has made the work of journalists and photojournalists easier (Dhirubhai Ambani Institute of Information and Communication Technology, DAIICT, 2013).

Aesthetics is very important to the success of any form of media today. It is especially important for Nigerian magazines and newspapers to have aesthetically appealing covers because it is believed that Nigerians naturally have a poor reading habit. If a newspaper or magazine is beautiful and properly packaged, it tends to attract readers attention to it. It is important to note that good cover images cause impulse buying. The aesthetic elements include size of the publication, typeface and size, white space, headlines as well as photographs and illustrations (Azi, 2013). Pictures erase language and literacy barriers, as they do not require the use of words or text to pass the messages across. Pictures are known to register more easily than words in the minds of readers, a quality which makes them pass messages faster (Onakpa, 2010). Early newspapers and magazines hardly used photographs because editors felt that they were a waste of space. Later, they realized that photographs attract readers and also beautify the publication. In Nigeria, the early magazines made use of few photographs due to technical limitations.

But every reporter in this information age is expected to have skill in several areas - news coverage, use of information technology devices, use of camera and many more. Media houses, therefore, have to provide their reporters with digital recording devices because the images taken-still or motion - need to be processed and edited probably in the shortest time possible. Thus, a journalist must be able to properly harness the skills of a videographer, photographer, layout designer, reporter and editor to make a good journalist in this era (DAIICT, 2013). 


\section{Determinants of Published Photo Quality}

Photographic quality is the standard of a photograph when it is compared to other photographs. Photo quality is usually assessed with indicators such as resolution, noise, dynamic range, brightness, contrast, texture and sometimes, editing (Bhattacharya, 2010). Dynamic range describes the ability of the camera to capture detail from the brightest highlight to the darkest shadows. It is the ratio of the lightest highlight level that a sensor or film can capture to the darkest (Goldstein D., 2009).

Resolution describes the ability of the camera to capture image detail in pixels. A camera's resolution is highly affected by the lenses that create the image, but where lenses are not the issue, the limit is dictated by the fine grain structure of the capturing media. Other determinants of photographic quality in magazine publishing such as clarity, contrast, exposure can be adjusted using photo manipulation programs in digital photography or during film development in film photography. If all other desired qualities are in place, paper quality could as well affwect the publishing outcome (Zelten, 2002).

\section{Photography and Innovation Adoption Research}

Photography does not seem to attract much research activity but some studies have been reported. Zhang \& Berger (2008) used Rogers' Diffusion of Innovations theory to determine the influence of technology evolution on technology adoption using digital cameras as a case study. They studied the sale of digital cameras in the USA and collected data using databases provided by research organizations. They also studied the evolution by formation of dominant designs and concluded that technological performance improvements and internal and external dominant designs have positive and significant influence on the sale of digital camera(Nieman,2010).

Against the background that mobile phones come with photographic cameras, Wilson \& Zelten (2002) conducted a study on the adoption of mobile phones by journalists in Borno State, Nigeria. The study was conducted on the framework of Diffusion of Innovations Theory and employed survey research method to gather data. They found that $100 \%$ of the respondents use mobile phone for contacting and interviewing news sources, $25 \%$ of the respondents use the mobile phone to record or cover audio and visual news events, $21 \%$ use the mobile phone to source for news online and perform other Internet activities. The study also reported that $100 \%$ of the respondents think that the mobile phone has made it easier to assess news and gather information while $88 \%$ believed that the mobile phone is a handy, convenient and affordable tool for newsgathering. Over $66.3 \%$ indicated that it has made journalism practices accessible to non-professional journalists whereas $8.6 \%$ think that mobile phones have made authentication of news sources difficult. They concluded that every profession including journalism is taking advantage of technological advancements. The study shows that journalists in Borno State, Nigeria, have extensively adopted the technology and use mobile phone for their journalistic assignments. It was, however, silent on whether they adopted digital cameras to improve photo quality (Zelten, 2002).

Kombol (2009) conducted a study on the adoption and diffusion of digital photography among journalists in Makurdi Town. The study examined the advantages of digital photography as well as the problems which photojournalists face in the adoption of this innovation. They conducted a survey of selected photojournalists across television stations, newspapers and magazine houses in Makurdi. The results indicate that $33.34 \%$ of the respondents believe that the most significant advantage of digital photography is that it saves time whereas $26.66 \%$ believe that the most significant advantage of digital photography is that it saves cost. Over $20 \%$ indicated that the most significant advantage is that it improves picture quality while $6.67 \%$ indicated that the most significant advantage of digital photography is that it eases editing and $13.33 \%$ indicate that the most significant advantage of digital photography is that it is compatible with computers. Most of the respondents (46.67\%) indicated that cost of new technology is the most pressing problem that prevents the adoption of digital camera while few (6.67\%) of the respondents believe that lack of service personnel is the most pressing problem that prevents the adoption of digital camera by photojournalists in Nigeria. They concluded that as far as photojournalists are concerned, the most significant advantage of digital photography is that it saves time because they need to meet a deadline. Cost of digital technology was perceived as the most pressing problem because digital cameras are quite expensive for an average photojournalist and they should be provided by the media organizations. These findings make it clear that not much has been done to investigate the relationship between improved photo quality and adoption of digital camera Kombol (2009).

\section{Theoretical Framework}

The theory of technological determinism expounded by Marshall McLuhan serves as a framework for this study. The theory assumes that national communication and group cultures are inevitably modified to suit technological developments that influence the lives of the people (Baran and Davis, 2003). Technological Determinists generally argue that media technologies shape how journalists, as well as others, think, feel, act, and operate as society moves from one technological age to another (Tribal- Literate- Print- Electronic). In other 
words, journalists adapt to new technologies so that they can send and receive messages (photographic or textual) like everyone else. Basically, it assumes that such technological developments, once under way, are unstoppable, make inevitable progress and subsequently become unavoidable and irreversible. In the case of digital camera the zeal with which it has been adopted seems to support the determinist position.

The theory is supported with Rogers' Diffusion of Innovation Theory which describes the innovation adoption process as one that involves five stages: Knowledge Stage, Persuasion Stage, Decision Stage, Implementation Stage and Confirmation Stage (Rogers, 1995). A clear understanding of the relationship between the adoption of digital camera and improved photo quality in magazines will help the numerous journalists who have adopted this technology to confirm its use and help those who are at the persuasion stage to decide whether to adopt or not (Rogers, 2003). Since the persuasion stage is a point when the individual is already interested in the innovation and seeks information about it, the findings of this study will be useful to such potential adopters. It is assumed that implementers often need technical assistance from change agents and others to reduce the degree of uncertainty about the consequences of innovations adopted (Sahin, 2006). Thus, it could be said that the theory provides a strong framework for the present study. Furthermore, this theory provides a suitable framework for the questions that border on innovation characteristics such as convenience of use, on- camera editing and speed. This is because it assumes that innovation characteristics impinge on the extent of adoption (Rogers, 2003).

\section{Methodology}

The study employed survey method in data collection using self-administered questionnaire. To analyse the data collected from the sample, the researcher made use of five-point Likert scale for measuring ordinal numbers and used nominal measures for the nominal and the dichotomous questions. With a list of Nigerian magazines obtained from Ifeduba (2011), the researcher selected the sample by following a procedure that involved five steps: Step 1: Adapting a list on which 19 magazine genres were identified. From these, the researcher purposively selected 9 popular magazine genres which represent about $80 \%$ of the Nigerian magazines. Step 2: Random selection of 350 magazines from the 9 selected genres. The photojournalists of the magazines houses selected were the respondents. Step 3: Where a magazine house has more than one photojournalist, the researcher picked the senior photojournalist. Step 4: Where the magazine houses outsource the photojournalism functions, the consulting photojournalist was selected. Step 5: Where two or more magazine houses make use of the same photojournalist, one of the magazine houses was replaced by another (Wimmer and Dominick, 2011). The researcher visited 252 of the respondents at their workplaces to administer the questionnaire. Sixty-eight were administered by electronic mail. The questionnaire was made up of closeended questions, open-ended questions and 6 Likert scale statements. The table below shows the selected magazine genres and the number of respondents chosen from each of them.

\section{Data Presentation and Analysis}

A total of 320 copies of the questionnaire were correctly filled and returned, therefore, leaving the researcher with a response rate of $91.4 \%$. Data were analysed using tables and charts.

Table 1: Frequency Distribution of Responses by Magazine Genres

\begin{tabular}{|l|l|l|l|}
\hline S/N & Magazine Genre & Respondents & Percent \\
\hline $\mathbf{1 .}$ & News Magazines & 10 & $3.1 \%$ \\
\hline $\mathbf{2 .}$ & Fashion Magazines & 50 & $15.6 \%$ \\
\hline $\mathbf{3 .}$ & Entertainment Magazines & 40 & $12.5 \%$ \\
\hline $\mathbf{4 .}$ & Society/Personality Magazines & 70 & $21.8 \%$ \\
\hline $\mathbf{5 .}$ & Other & 150 & $47 \%$ \\
\hline & Total & $\mathbf{3 2 0}$ & $\mathbf{1 0 0 \%}$ \\
\hline
\end{tabular}

Table 1 indicates that about $3 \%(n=10)$ of the respondents work with news magazines, $15.6 \%(n=5)$ of them work with fashion magazines, $12.5 \%(\mathrm{n}=40)$ of them work with entertainment magazines, $21.8 \%(\mathrm{n}=70)$ work with society/personality magazines, $47 \%(n=150)$ of them work with other genres of magazines.

Table 2: Perceived Level of Improvement in Photo Quality since Inception

\begin{tabular}{|l|l|l|l|}
\hline S/N & $\begin{array}{l}\text { Level of } \\
\text { Improvement }\end{array}$ & Frequency & Percentage \\
\hline $\mathbf{1 .}$ & Very High & 120 & $37.5 \%$ \\
\hline $\mathbf{2 .}$ & High & 190 & $59.4 \%$ \\
\hline $\mathbf{3 .}$ & Fairly High & 10 & $3.1 \%$ \\
\hline $\mathbf{4 .}$ & Low & 0 & $0 \%$ \\
\hline $\mathbf{5 .}$ & Very Low & 0 & $0 \%$ \\
\hline & Total & $\mathbf{3 2 0}$ & $\mathbf{1 0 0} \%$ \\
\hline
\end{tabular}


Table 2 indicates that over $37 \%(n=120)$ of the respondents recorded that there was a very high level of improvement in the photo quality of the magazine, $59 \%(\mathrm{n}=190)$ of them recorded high level of improvement, $3.1 \%(n=10)$ of the recorded fairly high level of improvement while none of them recorded low or very low levels of improvement. Almost all the respondents indicated that there has been a high or very high level of improvement in photo quality in the magazines they represent.

Table 3: Perceived Attributes that Attract Readers Most to the Magazines

\begin{tabular}{|l|l|l|l|}
\hline S/N & Attributes & Frequency & Percentage \\
\hline $\mathbf{1 .}$ & Quality Photographs & 15 & $47 \%$ \\
\hline $\mathbf{2 .}$ & News & 2 & $6 \%$ \\
\hline $\mathbf{3 .}$ & Features & 6 & $19 \%$ \\
\hline $\mathbf{4 .}$ & Cover model & 7 & $22 \%$ \\
\hline $\mathbf{5 .}$ & Others & 2 & $6 \%$ \\
\hline & Total & $\mathbf{3 2}$ & $\mathbf{1 0 0} \%$ \\
\hline
\end{tabular}

Table 3 indicates that a total of $47 \%(n=150)$ of the respondents think that quality photographs attract readers most to the magazines, $6 \%(n=20)$ think news attract readers most, $19 \%(n=6)$ of them think features attract readers most, $22 \%(n=70)$ of them think cover models attract readers most while $6 \%(n=20)$ of them think other attributes are responsible for it.

Table 4: Frequency Distribution of Year of Adoption of Digital Camera Per magazine House

\begin{tabular}{|l|l|l|l|}
\hline S/N & Year & Frequency & Percentage \\
\hline 1. & 2006 & 20 & $6.3 \%$ \\
\hline 2. & 2007 & 20 & $6.3 \%$ \\
\hline 3. & 2008 & 10 & $3.1 \%$ \\
\hline 4. & 2009 & 60 & $18.6 \%$ \\
\hline 5. & 2010 & 70 & $22 \%$ \\
\hline 6. & 2011 & 80 & $25 \%$ \\
\hline 7. & 2012 & 50 & $15.6 \%$ \\
\hline 8. & 2013 & 10 & $3.1 \%$ \\
\hline & Total & $\mathbf{3 2 0}$ & $100 \%$ \\
\hline
\end{tabular}

Table 4 indicates that $6.3 \%$ of the respondents started using digital cameras in 2006, $6.3 \%$ in 2007 , $3.1 \%$ in $2008,18.6 \%$ in $2009,22 \%$ in $2010,25 \%$ in $2011,15.6 \%$ in 2012 and $3.1 \%$ in 2013 . It indicates that among the respondents, $12.6 \%$ are early adopters, $21.7 \%$ of them are the early majority, $47 \%$ of them represent the late majority and the remaining $18.7 \%$ are the laggards.

Figure 1: Perceived Reasons for Improved Photo Quality in the Magazines

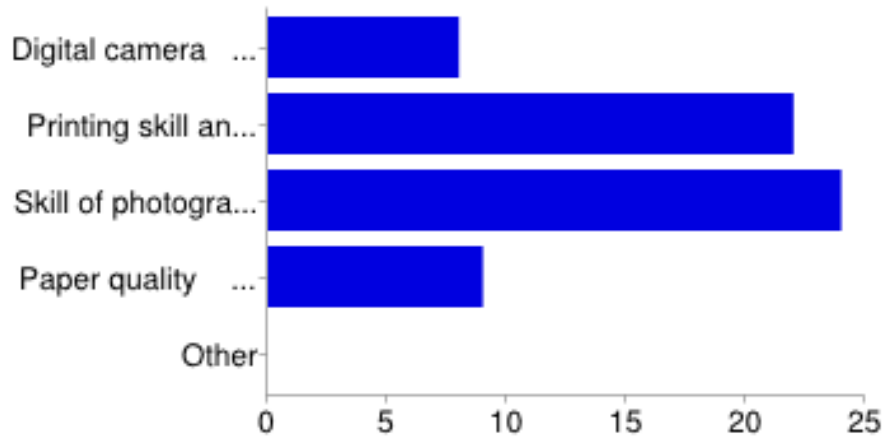

Figure 1 indicates that there were 81 responses for digital camera as the cause of improved photographic quality, there were 220 responses for printing skill and technique as the cause of improved photographic quality, there were 241 responses for skill of photographer as the cause of improved photographic quality and there were 9 responses for paper quality as the cause of improved photographic quality. This shows that even though some of the respondents think that digital camera is responsible for improved photographic quality in Nigerian magazines, majority of them think that skill of photographer and printing skill contribute to it more than use of digital camera.

\section{Correlation Coefficients}


With regard to the analysis, correlation coefficient value of 1 means that there is a perfect correlation between two variables. The values of correlation coefficients range between -1 and +1 . A positive (+ve) correlation coefficient value means that the two variables under investigation rise and fall together. On the one hand, there is a direct relationship between the two variables, as one variable increases, the other increases as well. On the other hand, a negative (-ve) correlation coefficient value means that the two variables have inverse relationship, which implies that as one increases, the other decreases. In this study, both scenarios exist (Table 9).

Table5: Improved picture quality and Technical skills/paper quality

\begin{tabular}{|l|l|l|l|}
\hline $\begin{array}{l}\text { Pearsons Correlation } \\
\text { coefficient for }\end{array}$ & $\begin{array}{l}\text { Photographic } \\
\text { skills }\end{array}$ & Printing skill & Paper quality \\
\hline $\begin{array}{l}\text { Technical Skills and } \\
\text { paper quality }\end{array}$ & $0.962^{*}$ & 0.657 & -0.649 \\
\hline Sig. (2-tailed) & .000 & .000 & .000 \\
\hline Number & 320 & 320 & 320 \\
\hline
\end{tabular}

\section{Correlation is significant at the 0.05 level (2-tailed)}

Table 5 indicates that there is a highly positive correlation between improved printing skill and improved photographic quality with a correlation coefficient value of +0.657 . In essence, improvement in the printing skill resulted in improved photographic quality in the selected magazines. In the same vein, improved photographic quality was found to be highly significant and positively correlated with improved photographic skills with a correlation coefficient value of +962 . This implies that increase in the skills of the photojournalists resulted in improvement in the photographic quality. Though the journalists indicated that paper quality is one reason for improved photo quality in there magazines, the correlation tests indicated that there is a negative significant relationship between improved photo quality and improved paper quality. In other words, improvement in paper quality may not lead to improvement in photo quality. The only explanation for this contradiction may be that paper alone as a factor of production cannot lead to improved picture quality except it is used together with other factors.

Table6: Improved picture quality and Innovation characteristics

\begin{tabular}{|l|l|l|l|}
\hline $\begin{array}{l}\text { Pearson's Correlation } \\
\text { coefficient for }\end{array}$ & Higher resolution & Convenience & $\begin{array}{l}\text { On-camera editing } \\
\text { capabilities }\end{array}$ \\
\hline $\begin{array}{l}\text { Innovation } \\
\text { characteristics }\end{array}$ & -0.336 & $0.995^{*}$ & $0.929^{*}$ \\
\hline Sig. (2-tailed) & .000 & .000 & .000 \\
\hline Number & 320 & 320 & 320 \\
\hline
\end{tabular}

Correlation is significant at the 0.05 level (2-tailed)

Table 6 indicates that there is a highly significant and positive correlation between the improved photographic quality and the convenience of the use of digital cameras by photojournalists with a correlation coefficient of +0.995 . In other words, the ease of use of the digital cameras resulted in the improvement in the photographic quality in the selected magazines. On-camera editing capability of the digital camera was also found to have a significant and positive correlation with the improved photographic quality of the Nigerian magazines. Similarly, the opinion of the respondents that digital photography would eventually supplant film photography has a significant and positive correlation with improved photographic quality with a correlation coefficient value of +0.997 . Higher resolution was negatively correlated with improved picture quality at -0.336 , implying that the higher resolution associated with digital cameras in the literature might not always lead to improved picture quality in publications. 


\section{Discussion of Findings}

The findings of this study indicate that there is a positive relationship between the adoption of digital cameras and improved photographic quality in Nigerian magazines. Furthermore, it revealed that digital camera is not the only determinant of improved photographic quality as improved photographic skill, improved printing skill and paper quality also result in improved photographic quality. The findings also indicate that there is a positive relationship between the adoption of digital cameras and the reduction of photographic noise in the selected magazines. This perception is contrary to the expert opinion of Osterman (2007) who claimed that even high-end professional digital cameras produce noise especially in darker areas of the photograph such as the dark shadows and middle dark shadows. The results show that printing skill is a very important determinant of photographic quality and is more significant than digital camera in determining photographic quality in Nigerian magazines.

In terms of gratifications for which journalists prefer digital camera to analogue, the findings indicate that speed and convenience are the two most important characteristics that motivate photojournalists to use digital camera for their journalistic assignments. As noted in the literature, speed and convenience are two advantages of digital cameras because it eradicates darkroom processes that came along with film camera. In a study that Wilson \& Gapsiso (2009) conducted on the adoption of mobile phones by journalists in Borno State, Nigeria, they concluded that the use of new technology like mobile phone for journalistic purposes is very convenient, handy and affordable. Findings of this study support their findings and seem to confirm that convenience is the major motivating factor for using digital camera and mobile phone for journalistic assignments. Kombol (2009) conducted a study on the adoption and diffusion of digital photography among journalists in Makurdi town and the results agree with the findings of this study. Kombol concluded that "cost of new technology" is the most pressing challenge faced by journalists who use digital camera for journalistic assignments. This study proves that Nigerian photojournalists have passed through all the stages of innovation diffusion and are currently in the confirmation stage where they prefer digital camera to film camera and only seek information that supports the decision. This agrees with Azi's (2003) conclusion that photojournalists in Nigeria have fully adopted the use of digital camera for their journalistic assignments.

Limitations of the Study and Areas of Further Research: This study focuses on magazines, one of the traditional media of mass communication. It only examines the photographic aspect of magazine production and focuses on the equipment used by only photojournalists. Online magazines are not studied in this research work because there is a difference in the assessment of printed photographs and online photographs. Screen resolution, screen brightness contrast and file compression are some of the considerations that make it unadvisable to study print and online photographs together. As technology gets better, cameras will get more advanced; and so the findings of this study may only be valid for some years because new developments that may modify the findings may arise. The list of magazines used for this study was compiled in year 2011. As years go by, more magazines will emerge and some will collapse. This may necessitate a longitudinal investigation.

\section{Conclusion and Recommendations}

On the basis of the findings, the study concludes that the adoption of digital camera has a positive relationship with improved photographic quality in Nigerian magazines. Therefore, digital camera is one of the factors responsible for improved photographic quality in magazines. It is also likely that digital camera will eventually, completely supplant film camera in the long run. But it must be noted that skill of photographers, printing skill and paper quality are very important factors in the improvement of photographic quality in magazines with skill of photographer being the most significant factor.

Recommendations: Nigerian magazine houses should ensure that they acquire necessary technology for better and higher quality photographic production, spend more time to improve the photographic skills of their photojournalists in order to ensure good photographic quality. Paper quality should not be taken for granted, as it is a very high determinant of photographic quality in magazines and printing in general. In line with the respondents' perception of printing skills, magazine houses should ensure that printing skill is given more attention because it is a very important factor that must be put into consideration for photographic quality to be good and professional. Similar studies covering offline magazines, newspapers and other publications should be conducted in order to arrive at more generalizable findings. Lastly, studies should be carried out using various methods of data collection, larger population sample and different sampling techniques in order to discover changes and also make additional knowledge available on the topic of study. 


\section{References}

[1]. Azi, J., Dakyes, S., Ogunwole, S. (2013). Use of photo-manipulation techniques in enhancing magazine cover portraiture: Lessons for journalistic graphics in Nigeria. Journal of Media and Communication Studies, 5, 72-77.

[2]. Baran,S and Davis (2003) Mass Communication Theory: Foundations, Ferment and Future. Belmot: Thomson Wadsworth.

[3]. Bhattacharya, S. (2010). A Framework for Photo-Quality Assessment and Enhancement based oVisual Aesthetics. Firenze: University of Central Florida

[4]. Cambridge-MIT Institute. (n.d.). On Rules, Routines and the Adoption of Technological Product Innovations: The Case of the Transition from Chemical Photography to Digital Imaging. Retrieved October 23, 2013, from www.csog.group.cam.ac.uk/iacr/papers/runde.pdf

[5]. Curtin, D. (2007). The Textbook of Digital Photography. Massachusetts. Retrieved October 30, 2013 from www.photocourse.com

[6]. DAIICT (2013). Journalism in the Age of Digital Technology. Online Journal of Communication and Media Technologies, 3 (1), $125-143$.

[7]. Dominick, R. D. (2000). Mass Media Research: An Introduction.Califonia: Wadsworth Publishing Company

[8]. Ekeanyanwu, T. N. (2009). ICT and Globalization in the Nigerian Society. Journal of Communication and Media Research, 1 (2), 13-29.

[9]. Goldstein, D. B. (2009). Physical Limits in Digital Photography. Leicester: Northlight Images.

[10]. Ifeduba, E (2010). "Emergence and Growth of Specialized Magazines in Nigeria" in International Journal of Communication and Performing Arts vol. 2 No. 1 pp. 16-24

[11]. Kombol, M. (2009). Adoption and Diffusion of Digital Photography among Journalists in Makurdi Town. Journal of Communication and Media Research, 1 (2), 31-44.

[12]. Nieman, A. (2010). Visual Journalism: Fresh Approaches and New Business Strategies for Multimedia Age, Massachusetts. Bob Giles.

[13]. Onakpa, M. (2010). Photographs as Tools for Cultural Imperialism in The Sun and Vanguard Newspapers. In A. C. Education, Perspectives on Communication and Culture. Uyo: BSM Resources Nig. Ltd.

[14]. Osterman, M., Grant, B. (2007).History and Evolution of Photography.The Focal Encyclopedia of Photography, 27-36

[15]. Osterman, M., (n.d.). History and Evolution of Photography. Retrieved October 29, 2013, from www.pacificrimcamera.com

[16]. Rogers, E. (1995). Diffusion of Innovations. New York: New York Free Press.

[17]. Rogers, E. (2003). Diffusion of Innovations (5th ed.). New York: The Free Press.

[18]. Sahin, I. (2006). Detailed Review of Rogers' Diffusion of Innovations Theory and Educational Technology-Related Studies Based on Rogers' Theory. The Turkish Online Journal of Educational Technology, 5 (2), 14-23.

[19]. Wilson, J., \& Gapsiso, N. (2009). Use of Mobile Phones by Journalists in Borno State, Nigeria. Journal of Communication and Media Research, 1 (2), 105-114.

[20]. Zhang, M., \& Berger, P. (2008). The Influence of Technology Evolution on Technology Adoption: A Study of Digital Cameras. California: Academy of Management Conference.

[21]. Zelten, J. P. (2002). Digital Photogapahy and the Dynamics of Technology Innovation. Massachusetts: Massachusetts Institute of Technology. 